\title{
Evaluation of Smile Line in Natural and forced Smile Position: An Institution-based Study
}

\author{
Dr Binam Sapkota,' Dr Shatakshi Srivastava, ${ }^{2}$ Dr Sushmit Koju, ${ }^{3}$ Dr Ritesh Sriï \\ 'Asst Prof, Dept of Prosthodontics, ${ }^{2} L e c t u r e r$, Dept of Community \& Public Health Dentistry, \\ ${ }^{3}$ Dental Surgeon, 4Lecturer, Dept of Oral Pathology \\ Kathmandu University School of Medical Sciences, Dhulikhel, Nepal
}

\section{ABSTRACT}

Introduction: Smile line is a major factor considered in esthetic treatment planning.

Objective: To assess the position of the smile line both in natural and forced position in relation to age and gender in Nepali population sample.

Materials \& Method: A cross sectional study was done in 220 adults. DSLR camera was used to take photograph of the participants. Two different photographs were taken of each participant in natural and forced smile position in standardized format. The smile lines were determined and classified according to Liebart et al. Data analysis was done by SPSS 20.0 software. Chi square test was performed to analyze statistical significance between the gender and age groups

Result: Maximum individuals had low type of natural smile (59.1\%) and average type of forced smile (40.0\%). Very few individuals had very high type of natural smile (1.4\%) and very high type of forced smile (15.9\%). Among all, $41 \%$ had visibility of the periodontium during normal smile while on forced smile $79.1 \%$ had visibility of the periodontium.

Conclusion: Females have significantly more periodontal visibility when compared to males during forced smile in Nepali population sample. This concept of smile line should be utilized for treatment planning to achieve desirable facial esthetics in many fields of dentistry including Orthodontics, Prosthodontics, Periodontics, Restorative Dentistry.

Keywords: esthetics, periodontium, smile, smile line

\section{INTRODUCTION}

Smile is an involuntary action denoting happiness, pleasure, sociability, appreciation or amusement. It comes from inner satisfaction and is a means of nonverbal communication. It evolved from a need to communicate and is contagious. Smile plays an important role in social acceptance, interaction, and development of personality.

Frush and Fisher ${ }^{1}$ and Jameson ${ }^{2}$ discussed the concept of smile line and defined it as "the harmony between the curvature of the incisal edges of the maxillary anterior teeth and the upper border of the lower lip'. According to Sarbi; ${ }^{3}$ smile line (lip line) is the amount of vertical tooth exposure. On smiling the height of the upper lip relative to the maxillary central incisors and line depends on six factors; upper lip length, lip elevation, vertical maxillary height, crown height, vertical dental height, and incisor inclination.

A bit of gingival display is acceptable and is considered a sign of youthful appearance. ${ }^{4}$ When the smile line is above the cemento-enamel junction (CEJ); it is regarded as 'gummy smile' which is considered undesirable. ${ }^{5}$ The initial point of a smile is the lip line at rest, with an average maxillary incisor display of $1.91 \mathrm{~mm}$ in male and nearly twice that amount i.e. $3.40 \mathrm{~mm}$ in female. ${ }^{6}$ Smile line can be used as a valid tool for assessment of the esthetic appearance of a smile and can be applied universally.?

Smile involves the teeth including its shape, size, color, position and also visible healthy periodontium. Its evaluation provides information about the teeth and surrounding mucosa which is an essential factor for esthetic dentistry. This factor makes the assessment of smile line a quintessential element for many fields in dentistry including orthodontic treatment. Most of the studies had analyzed only a natural smile. However, forced smile should also be taken into consideration during esthetic planning because the patient can exhibit more periodontium during the forced smile. Hence the present study determined the smile line classification as per Liebart et $a l^{8}$ which considered smile, in both the natural and forced smile as well as the amount of periodontium visibility. The objective 
of the study was to assess the position of the smile line in both the natural and forced smile in relation to age and gender in a Nepali population sample.

\section{MATERIALS AND METHOD}

A cross sectional study was done on 220 participants who visited Dental Department of Kathmandu University School of Medical Sciences, Dhulikhel Hospital. Approval was obtained from Institutional Review Committee, KUSMS to conduct the study. The study population was: subjects aged more than 18 years with at least eight contiguous maxillary anterior teeth which were equally distributed between right and left sides with healthy periodontium. Participants who had excessive attrition, anterior teeth rehabilitation and/ or presence of any gross facial asymmetry were excluded. All involved participants were informed about the purpose of the study and verbal

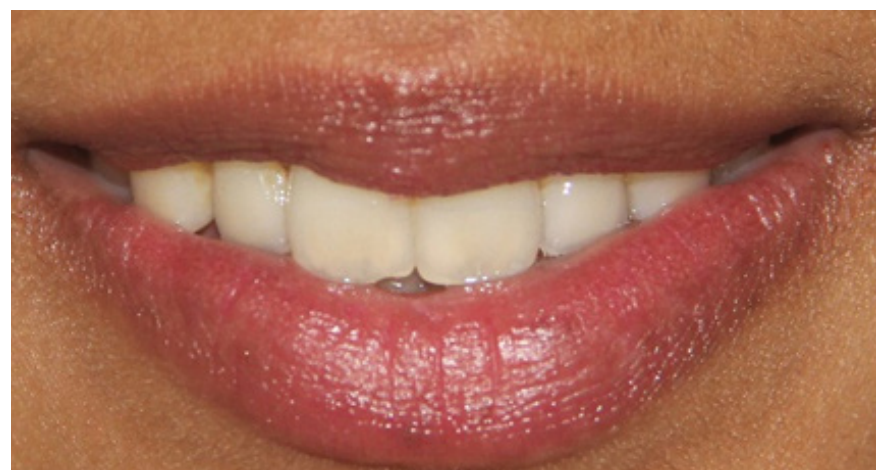

Figure 1a: Normal Smile

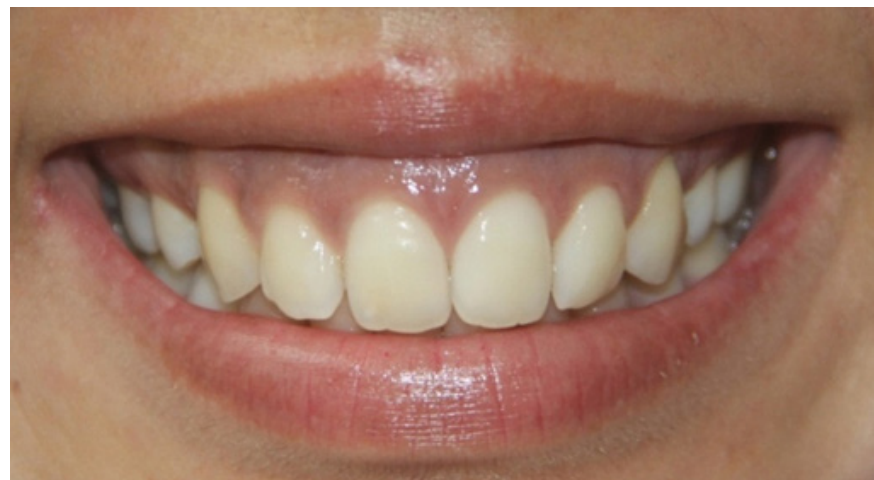

Figure 2a: Class 1 (Very high smile line)

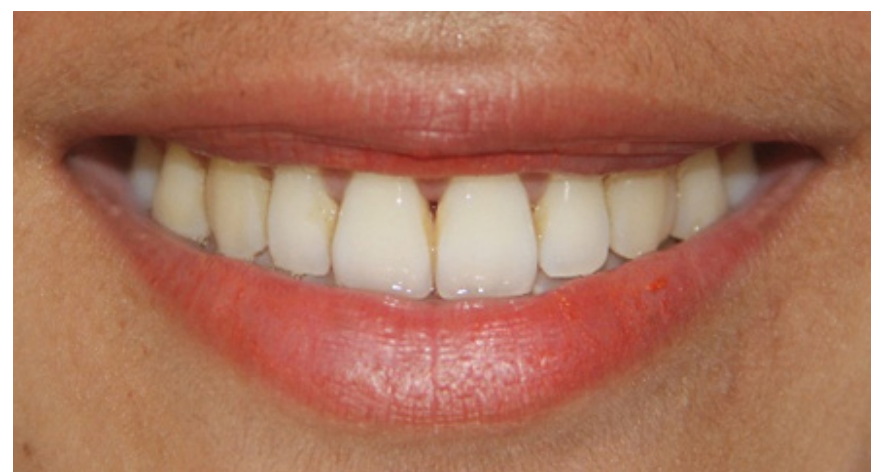

Figure 2c: Class 3 (Average smile line) consent was obtained. The participants were divided into gender and age categories; based on the age they were grouped as 18-35 years, 36-50 years and $>51$ years.

DSLR Canon EOS-60D camera was used to take photographs with the resolution of 18 Megapixels, $7.5 \mathrm{X}$ zoom, 18-135mm $(29-216 \mathrm{~mm}$ eq) lens. Two different sets of photographs were taken of each participant in natural and forced smile position. The photographs were standardized as per Liebart et $a l^{;}$by positioning the headrest in Frankfort horizontal plane assuring for proper angulations at a fixed distance of $30 \mathrm{~cm}$. Photographs were evaluated by 3 examiners and findings were recorded. The whole procedure was blinded. Data analysis was done using SPSS 20.0 software. Chi square test was performed to analyze statistical difference between the groups. The level of significance was set at $p<0.05$.

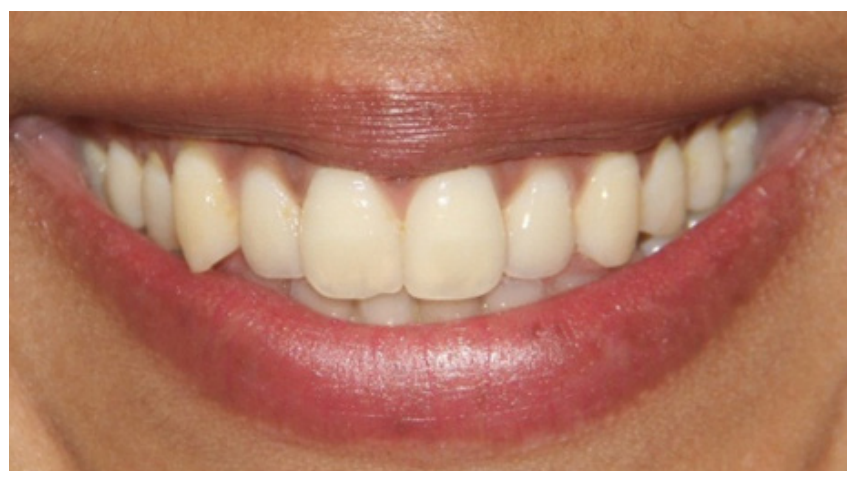

Figure 1b: Forced Smile

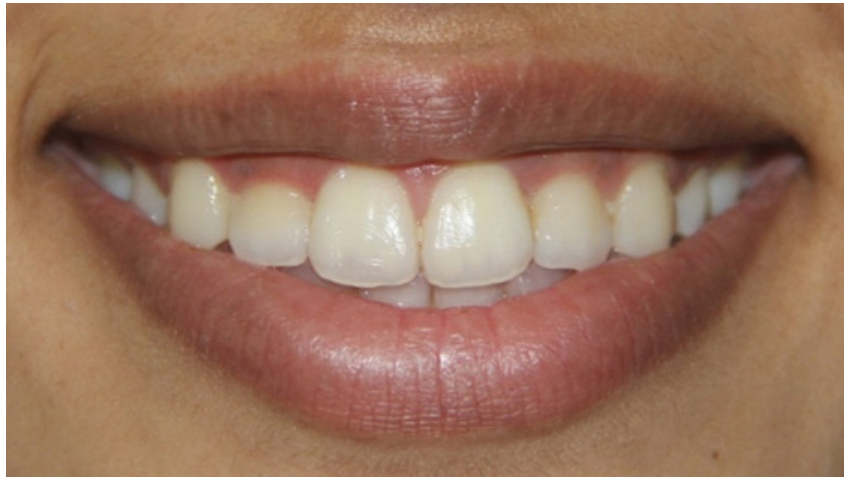

Figure 2b: Class 2 (High smile line)

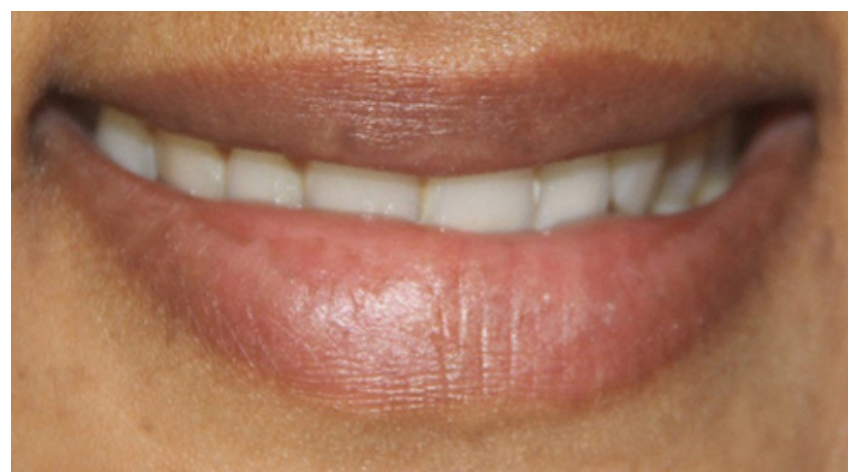

Figure 2d: Class 4 (Low smile line) 


\section{Classification of Smile Line}

Natural smile (Figure 1a) and forced smile (Figure 1b) were examined according to Liebart classification. ${ }^{8}$

- Class 1 (Very high smile line): More than $2 \mathrm{~mm}$ of marginal gingiva visible or more than $2 \mathrm{~mm}$ apical to the CEJ visible for the reduced but healthy periodontium. This could be the 'gummy smile' (Figure 2a).

- $\quad$ Class 2 (High smile line): Between 0-2 mm of marginal gingiva visible or between 0-2 $\mathrm{mm}$ apical to the CEJ visible for the reduced but healthy periodontium (Figure 2b).

- Class 3 (Average smile line): Only gingival embrasures are visible (Figure $2 \mathrm{c}$ ).

- Class 4 (Low smile line): Gingival embrasures and CEJ are not visible (Figure 2d).

\section{RESULT}

The study comprised of 220 participants including 118 (53.63\%) females and 102 males (46.36\%) with the age range of 18-62 years and a mean age of 31.22 years. Among all, most of the participants belonged to age group of 18-35 years (89 females, 67 males).

The results of the study are presented in Graph 1. Among the total participants maximum individuals have low type of natural smile $(59.1 \%$ ) and average type of forced smile (40.0\%). The least number of individuals possessed very

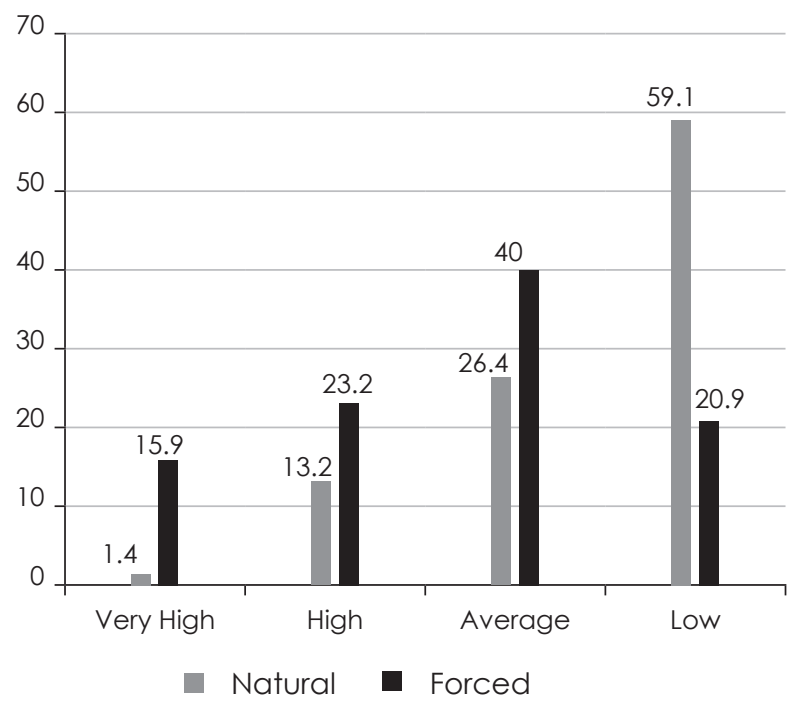

Graph 1: Distribution of subjects according to the classification of natural and forced smile (\%) high type of natural smile (1.4\%) and very high type of forced smile (15.9\%). It was found that, $41 \%$ of the total study population had visibility of the periodontium during normal smile. However during forced smile, $79.1 \%$ had periodontium visibility (Class 1+ Class $2+$ Class 3 ) and $39.1 \%$ revealed CEJ during forced smile (Class 1+ Class 2).

Table 1 shows the frequency distribution of the subjects according to age and gender during natural and forced smile. The frequency distribution of natural smile and forced smile according to gender are presented in Graph 2 and 3 respectively. Maximum number of males (72.5\%) and females (47.5\%) had low type of natural smile line. Similarly, maximum numbers of males (43.1\%) and females (37.3\%) had average type of forced smile line.

Females (52.5\%) were more likely to show their periodontium than males $(27.5 \%)$ (Class 1+ Class 2+ Class $3)$. However, this difference was not statistically significant $(p=0.145)$. Likewise, females $(89.0 \%)$ were more likely to show their periodontium than males (67.6\%) (Class 1+ Class 2+ Class3). This difference was statistically significant for forced smile $(p=0.016)$.

Frequency distribution of natural smile and forced smile according to age group are presented in Graph 4 and 5 respectively. Among all; 18-35 years group had highest number of low smile line (58.3\%), followed by average (26.9\%), high (13.5\%) and very high type (1.3\%). In 18-35 years age group, maximum individuals had average type of smile line $(39.1 \%)$, followed by high type $(28.2 \%)$, very high type (16.7\%) and low type (16.0\%).

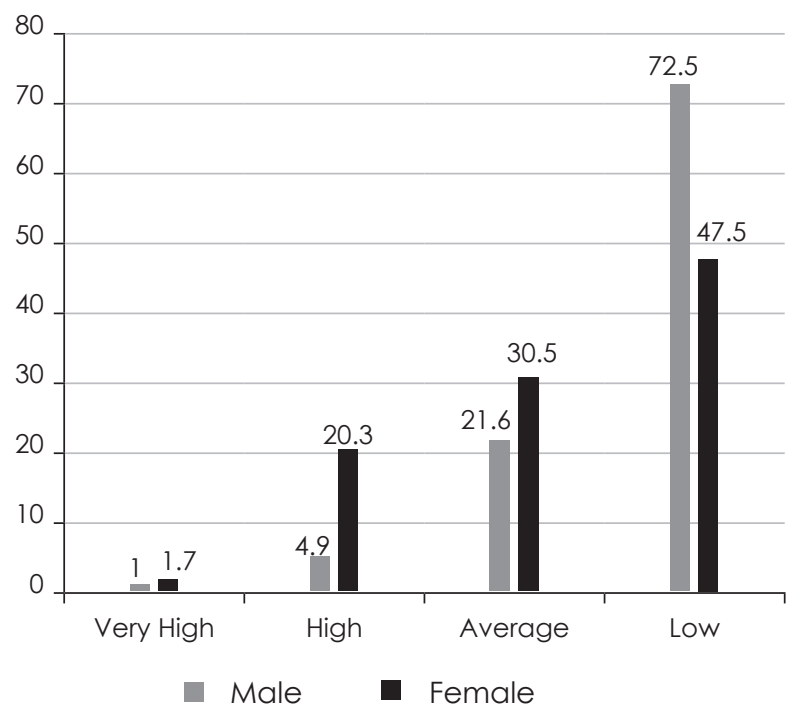

Graph 2: Distribution of natural smile line according to gender (\%) 


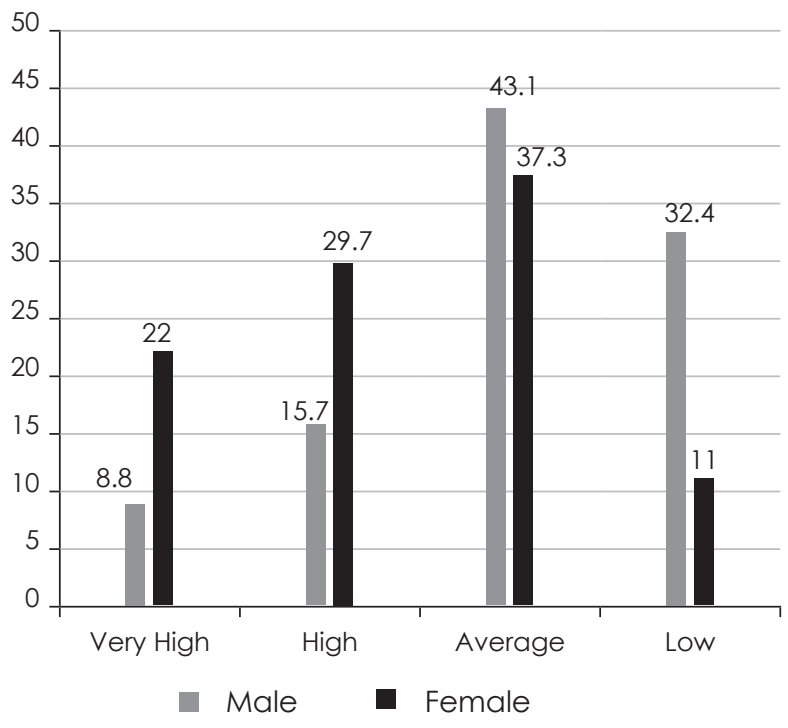

Graph 3: Distribution of forced smile line according to gender (\%)

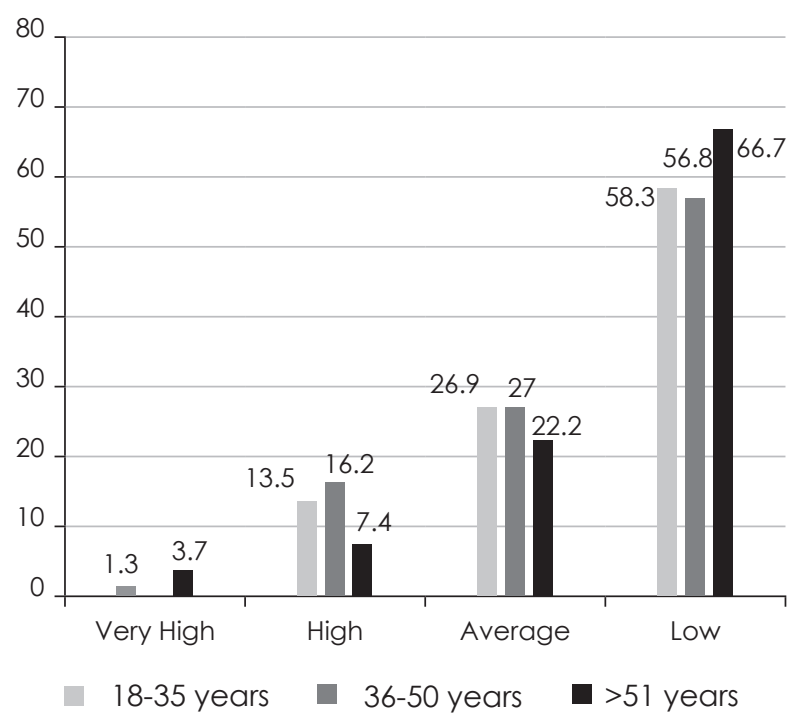

Graph 4: Distribution of natural smile line according to age group (\%)

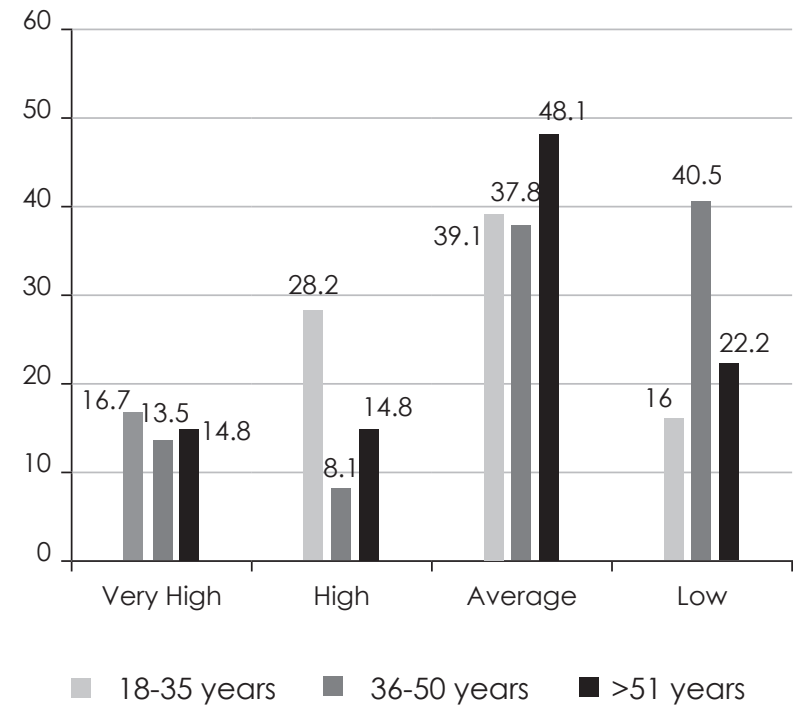

Graph 5: Distribution of forced smile line according to age group (\%)

Table 1: Frequency distribution according to age, gender, natural smile and forced smile

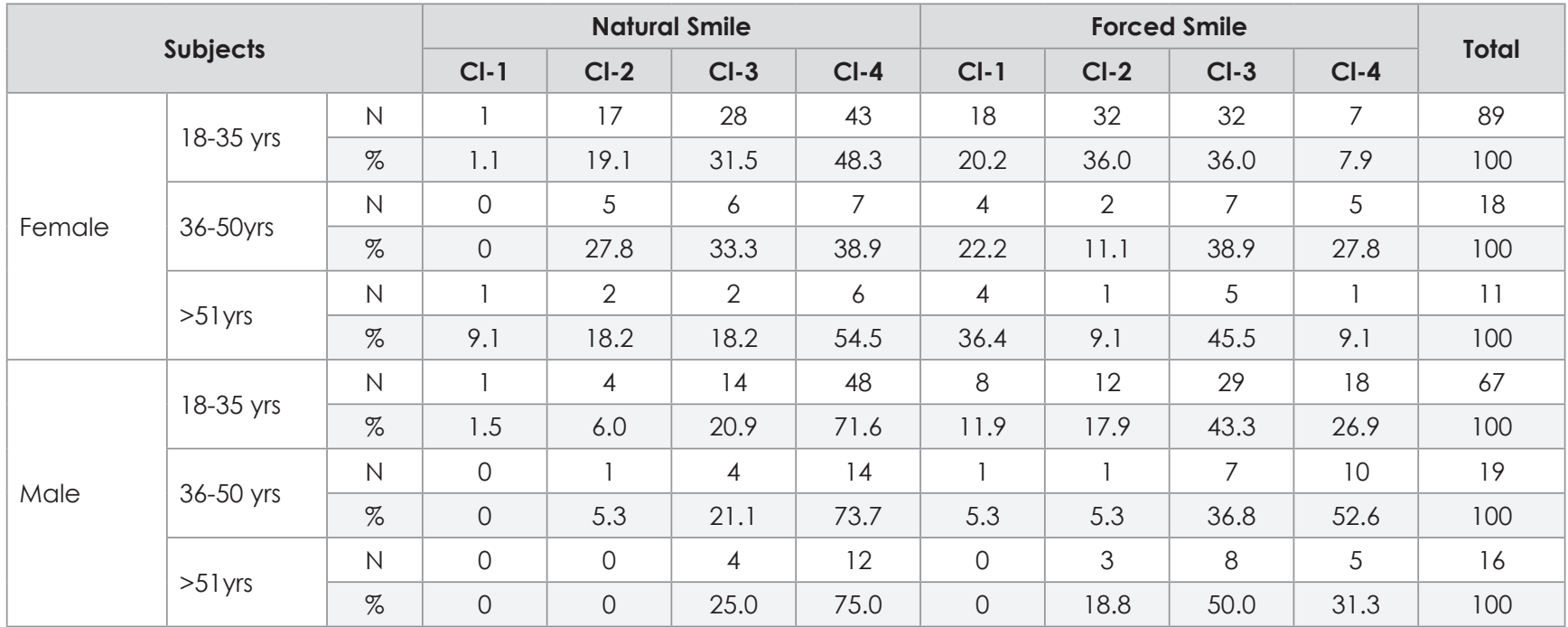




\section{DISCUSSION}

The classifications of smile line by Tijan et $a l^{5}$ did not specify the type of smile and Jensen et $a /^{13}$ only evaluated the natural smile. Therefore, the classification by Liebert et $a l^{8}$ is more functional as it considers smile line in both natural and forced smile positions. It also takes interdental papilla into consideration. The inclusion of forced smile in classification is important as $79.1 \%$ of individuals in the present study had periodontium visibility during forced smile, out of which in $39.1 \%$ CEJ was also visible.

In Nepali population sample, maximum participants had low type of natural smile $(59.1 \%$ ) and average type of forced smile (40.0\%). This is similar to a previous finding of Dayakar et al in Indians where low type of smile line for normal smile (67\%) and average type for forced smile (44\%). 9 Another similar study by Sereen et al in Saudi Arabian subjects revealed majority of the participants had low type of normal smile line $(41 \%) .{ }^{10}$ The findings of the present study were slightly different from study done in Europe by Liebart et al, ${ }^{8}$ where most common type was average type for both normal (44.79\%) and forced smile $(45.49 \%)$.

In our study least percentage of participants had very high type of natural smile $(1.4 \%)$ and very high type of forced smile (15.9\%). This finding differed from previous study done by Liebert et $a /^{8}$ where least common was very high type of natural smile $(4.69 \%)$ and low type of forced smile (10.94\%).

In the present study, females displaying natural smile showed a much higher percentage of high (20.3\%) and average $(30.5 \%)$ types of smile line compared to males who had only $4.9 \%$ of high and $21.6 \%$ average types of smile line. Maximum males had low type of smile line (72.5\%). This finding was similar to other studies by by Mark et $a{ }^{11}$ and Garg et $a .^{12}$ Another study by Sereen et al revealed that females exhibited higher smile line and very high smile line $\left(51.7 \%\right.$ and $37.8 \%$ respectively). ${ }^{10}$ Overall, Low type of smile lines were a masculine characteristic whereas high type of smiles were a feminine trait. ${ }^{5}$

For forced smile, maximum numbers of males (43.1\%) and females (37.3\%) had average type of smile line. This finding is similar to study done by Liebert et $a^{8}{ }^{8}$ in which maximum males (50.5\%) and females (42.9\%) had average type of forced smile. The least numbers of male had very high type of forced smile line (8.8\%). For females, the least prevalent was low type of forced smile (11\%). This clearly highlights the fact that females have a more broad type of forced smile; because of which low type of smile is least prevalent. Also, Females (89.0\%) were more likely to show periodontium than males $(67.6 \%)$ and this difference was statistically significant $(p=0.016)$.

Higher percentage of participants above 51 years age group had low type of smile line (66.7\%) in comparison to other younger age groups. Among $18-35$ years (13.5\%) and $36-50$ years ( $16.2 \%)$; maximum percentage of participants showed high and very high type of smile lines. These findings indicate that the high type of smile line during young age changes to low type in older age. This finding is consistent with previous studies done by Jensen et $\mathrm{al}^{13}$ who noted that the position of smile line was significantly lower with age. It was suggested that the facial height decrease with age so upper lip may change its dimension with ageing. It was also hypothesized that the elasticity of soft tissues has a tendency to decrease with age due to age related alterations in connective tissue metabolism, causing 'sinking' of the facial tissues. This finding is consistent with our findings that, in forced smile analysis wherein 36-50 years participants had $40.5 \%$ low type and $37.8 \%$ average type of smile, and $>51$ years participants had $22.2 \%$ low type and $48 \%$ average type of smile. In age group 18-35 years, a much higher percentage of high (28.2\%) and very high (16.7\%) type of smile were noted. In comparison with Liebert's study; ${ }^{8}$ normal smile had similar findings to our study but differed in forced smile, on agewise analysis.

As the present study was cross-sectional institutionalbased study with convenience sampling procedure; there could be a selection bias. For further research, longitudinal studies with a larger sample size and randomization among general population would be recommended.

\section{CONCLUSION}

Overall, females have significantly more periodontal visibility when compared to males during forced smile. This study highlights various types of smiles on the basis of gender and age in a Nepali population sample. Smile line can be used as a valid tool to assess the esthetic appearance by orthodontists and other clinicians. 


\section{REFERENCES}

1. Frush JP, Fisher RD. The dynesthetic interpretation of the dentogenic concept. J Prosthetic Dent. 1958; 8(4):558-81.

2. Jameson WS. Dynesthetic and dentogenic concept revisited. J Esthetic Restorative Dent. 2002; 14(3):139-48.

3. Sabri R. The eight components of a balanced smile. J Clin Orthod. 2005; 39(3):155-67.

4. Kokich VO, AsumanKiyak H, Shapiro PA. Comparing the perception of dentists and lay people to altered dental esthetics. J Esthetic Restorative Dent. 1999; $11(6): 311-24$.

5. Tjan AH, Miller GD, The JG. Some esthetic factors in a smile. J Prosthetic Dent. 1984; 51 (1):24-8.

6. Vig RG, Brundo GC. The kinetics of anterior tooth display. J Prosthetic Dent. 1978; 39(5):502-4.

7. Passia N, Blatz M, Strub J. Is the smile line a valid parameter for esthetic evaluation? A systematic literature review. Euro J Esthetic Dent. $2011 ; 6(3)$.

8. Liébart MF, Fouque-Deruelle C, Santini A, Dillier FL, Monnet-Corti V, Glise JM, Borghetti A. Smile Line and Periodontium Visibility. Period Practice Today. 2004; 1 (1):17-25.

9. Dayakar MM, Shipilova A, Rekha M. Evaluation of smile esthetics by photographic assessment of the dento-labio-gingival complex. J Dent Allied Sci. 2015; 4(2):65.

10. Sereen I. El Sarrag, Dr. Amal H. Abuaffan. The smile line in a sample of a Sudanese population. Glob J Med Resh: K Interdisciplinary. 2014; 14(6): Version 1

11. Hochman MN, Chu SJ, Tarnow DP. Maxillary anterior papilla display during smiling: A clinical study of the interdental smile line. Intl J Period Restor Dent. 2012; 32(4):375.

12. Garg S, Rathee SK. Smile analysis in Haryanavi females. IJMDS, www.jimds.org, 2013; 2(2).

13. Jensen JÖ, Joss AN, Lang NP. The smile line of different ethnic groups in relation to age and gender. Acta Med Dent Helv. 1999; 4(2):38-46. 